\title{
INSTITUIÇÕES DISCIPLINARES PARA A INFÂNCIA NA MANAUS VARGUISTA: ESCOLA PREMONITÓRIA DO BOM PASTOR E SECÇÃO MELLO MATTOS*
}

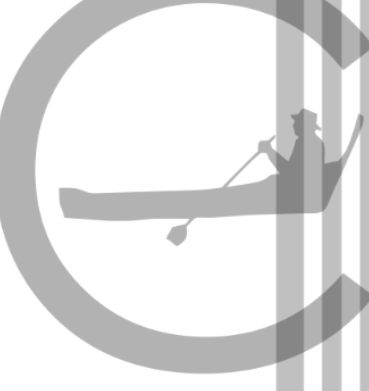

Alba Barbosa Pessoa ${ }^{1}$

\begin{abstract}
Resumo
O objetivo deste artigo é refletir sobre algumas das instituições disciplinares que se voltaram para infância na cidade de Manaus dos anos 30 e 40, bem como, sobre o cotidiano vivenciado dentro desses estabelecimentos. Seguindo diretrizes do Governo Federal, tais instituições foram criadas com a finalidade de "regenerar" crianças e jovens considerados delinquentes pelo Código de Menores vigente. Na perspectiva de incutir valores morais e cívicos aos filhos das famílias empobrecidas, meninas e meninos foram encaminhados a reclusão.
\end{abstract}

Palavras chaves: Infância; Trabalho; Disciplinarização

\begin{abstract}
The purpose of this article is to reflect on disciplinary institutions for children in the city of Manaus from the 1930s and 1940s, as well as on their everyday experiences within such places. The Federal Government created these institutions with the purpose of "regenerating" children and youth that were considered delinquent by the contemporary Code of Minors. As a consequence, girls and boys were put into seclusion under the state assumption that it was their role to instill moral and civic values to the children of impoverished families.
\end{abstract}

Keywords: Childhood; Labor; Disciplinarization.

\footnotetext{
* Fragmento da tese intitulada Pequenos Construtores da Nação: disciplinarização da infância na cidade de Manaus (1930-1945). Pesquisa realizada com bolsa de estudo FAPEAM.

${ }^{1}$ Doutora em História Social pela Universidade Federal do Pará.
} 
No decorrer dos anos 30 e meados dos anos 40, a infância recebeu especial atenção das autoridades públicas brasileira, vindo a tornar-se política governamental do então presidente Getúlio Vargas. Diversas políticas públicas foram implementadas visando reduzir o elevado número da mortalidade infantil que ceifava precocemente a vida de pequenos ou futuros trabalhadores. Em nome de um projeto de nação pautado na Educação, Saúde e Trabalho, às crianças foram direcionadas medidas de assistência, saúde e proteção. Nesse momento se colocou em curso um processo disciplinador para a infância empobrecida, no qual a proteção da criança poderia vir a tornar-se sinônimo de amparo e reclusão.

A cidade de Manaus não esteve apartada desse processo e no decorrer dos anos 30 e 40, uma rede de instituições disciplinares se voltaram para a infância com a finalidade última de encaminhamento de crianças para o mundo do trabalho. Dentro dessa rede de estabelecimentos destacamos o Juízo de Menores, a Escola Premonitória do Bom Pastor e a Secção Mello Mattos. O Juízo de Menores, criado em 1935, tinha sob sua jurisdição os menores considerados abandonados e delinquentes na faixa etária de até dezoito anos ${ }^{2}$. Entendemos que o termo "menor abandonado" pode ser sintetizado pela definição utilizada pelo governador do Amazonas, Álvaro Maia, em Mensagem enviada para a Assembleia Legislativa no ano de 1936. Para o referido governador "como abandonados devem ser tidos os filhos de paes pobres, que lhes não podem proporcionar o ensino necessário a tornal-os cidadãos uteis a sociedade"3. O Juizo de Menores desempenhou atuação emblemática, atuando de forma incisiva e invasiva na vida das famílias empobrecidas da capital amazonense. Engendrando verdadeiro combate as formas de sociabilidade das crianças, desencadeou ações de vigilância e repressão a esses pequenos e seus responsáveis, resultando em conflitos com a população que terminantemente se recusava a mudar seus modos de vida. Procurando abarcar todos os aspectos da vida das crianças que pelo Juízo de Menores passaram, nessa instituição se fazia o registro do perfil social, econômico e psicológico desses menores. Por meio de questionários, testes, medições antropométricas e outros recursos ditos científicos, se procurava abarcar esses pequenos no mais íntimo do seu ser ${ }^{4}$. Àqueles que

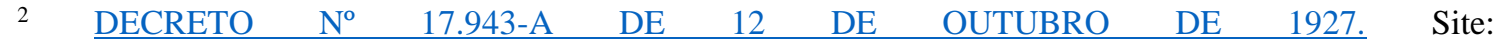
http://www.planalto.gov.br/ccivil 03/decreto/1910-1929/D17943A.htm.

${ }^{3}$ Mensagem do governador Álvaro Maia, dirigida a Assembleia Legislativa em maio de 1936. Manaus: Imprensa Pública. 1936.p.15.

${ }^{4}$ Sobre atuação do Juízo de Menores em Manaus ver: Pessoa, Alba Barbosa. Pequenos Construtores da Nação: disciplinarização da infância na cidade de Manaus (1930-1945). Tese de Doutorado. UFPA: 2018. 
reiteradamente se recusassem ao enquadramento social estava destinada a reclusão. As meninas seriam encaminhadas à Escola Premonitória do Bom Pastor, enquanto os meninos seriam encaminhados a Secção Mello Mattos ${ }^{5}$.

Em pesquisa para a cidade de São Paulo, Luís Ferla assevera que as instituições voltadas para os menores teriam quatro atribuições fundamentais: sequestração; tratamento e regeneração; estudo sistemático sobre o menor; melhor conhecimento das causas da criminalidade no país ${ }^{6}$. A sequestração seria a retirada da sociedade dos menores considerados delinquentes ou potencialmente delinquentes; o estudo sistemático desses menores definiria o seu tratamento no sentido de regenerá-lo. Tal estudo possibilitaria maior conhecimento sobre a criminalidade viabilizando a criação de formas mais adequadas de combatê-la ${ }^{7}$. Importa destacar que tais estabelecimentos foram pensados e criados visando atuar sobre um segmento social específico, no caso, as crianças e jovens empobrecidos.

Funcionando em regime de reclusão, ambas instituições, Escola Premunitória do Bom Pastor e Secção Mello Mattos, utilizavam de rígida disciplina na tentativa de incutir valores morais e cívicos aos seus internos, como veremos a seguir.

\section{Escola Premunitória do Bom Pastor}

Funcionando em regime de internato, a Escola Premunitória Bom Pastor estava voltada para a reeducação de menores do sexo feminino. Criada em 1940, preconizava como princípio o amor à pátria, o respeito às leis e o sentimento de cooperação ${ }^{8}$. Entendemos que a finalidade da instituição estava subentendida na denominação da própria escola pois Premunitória significa aquilo que prenuncia, ou seja, os modos de vida das meninas indicavam uma tendência para a prostituição. Enquanto Bom Pastor estava relacionado com aquele que procurava resgatar a ovelha desgarrada do rebanho. Neste caso, caberia ao Estado zelar pelas meninas que eles acreditavam se encontrar na eminência de se perder moralmente devido a condição de "abandono" em que se encontravam.

A localização da Escola, no Bairro Cachoeirinha, pode ser muito significativa. Este era um bairro habitado predominantemente pela classe trabalhadora, segmento pobre

\footnotetext{
${ }^{5}$ Trabalha com essas instituições a partir de outra perspectiva: VASCONCELOS, Kelly Rocha de Matos. Parques Infantis no Amazonas: 1940 a 1946. Dissertação de Mestrado em Educação. UFAM: 2018.

${ }^{6}$ FERLA, Luis. Feios, sujos e malvados sob medida: a utopia médica do biodeterminismo, São Paulo (19201945). São Paulo: alameda, 2009. P.270,271.

${ }^{7}$ FERLA, sujos e malvados sob medida...op.cit. P.270,271.

${ }^{8}$ Diário Oficial, $\mathrm{n}^{\circ}$ 13.505. Manaus, 07 de agosto de 1940. p.1.
} 
da população. Visando atender as filhas dessas famílias, que pela sua condição social eram consideradas abandonadas, a Escola Premunitória encontrava nessa localidade um campo fértil para suas atividades. As fábricas de beneficiamento de castanhas e de juta instaladas nesse logradouro tinham na mão de obra feminina a sua maior força de trabalho. Diariamente um elevado número de mulheres com suas filhas se dirigiam para longas jornadas de trabalho dentro das fábricas. Aquelas que não acompanhavam as mães na faina diária e não tinham uma outra ocupação eram consideradas predestinadas a seguir uma vida desregrada por passarem parte do dia de forma "improdutiva", longe dos valores morais desejados ao sexo feminino. Recebida com júbilo pela imprensa, o Jornal do Comércio anunciou que o estabelecimento educacional era "um exemplo de moralidade, um incentivo para o bem e uma luz a iluminar-lhes o caminho do trabalho, do dever e da justiça"9.

No ato da inauguração a Escola Premunitória não pôde contar com o funcionamento imediato das oficinas previstas tais como as de costura, bordado, cozinha, encadernação, vimaria, lavanderia, etc. Os parcos recursos advindos ante a permanente crise financeira pela qual passava o orçamento público, não permitiram a compra de máquinas e material adequados, sendo sua instalação realizada de forma gradual. O próprio regulamento da instituição estabelecia que "a instalação se fará de pouco a pouco, com o concurso das próprias menores e de pessoas caridosas" ${ }^{10}$. Em outras palavras, a instituição seria aparelhada por meio dos serviços prestados pelas próprias educandas, posto que na falta de recursos público o trabalho das meninas e as doações seriam revertidos em equipamentos e material necessário para a Escola. Também fazia parte das atividades desenvolvidas pela instituição o cultivo de hortas, a jardinagem e criação de galináceos. Partindo do princípio que "pelo trabalho e pela disciplina as menores se prepararão para uma vida social útil e produtiva", o cotidiano dessas pequenas, muito provavelmente, deveria se resumir, em grande parte, a atividades laborais ${ }^{11}$. Essa reflexão pode ser reforçada pelo quadro de funcionários da Escola Premunitória. Composto apenas por uma administradora, uma economista, uma inspetora vigilante, um médico, um dentista e professoras, todas as demais atividades seriam realizadas pelas educandas, bem

\footnotetext{
${ }^{9}$ Jornal do Comércio, $\mathrm{n}^{\text {o }}$ 12055. Manaus, 23 de março de 1940. p.1

${ }^{10}$ Diário Oficial do Amazonas, $n^{\circ}$ 13.505. Manaus, 07 de agosto de 1940. p.1

${ }^{11}$ Diário Oficial, $n^{\circ} 13.505$. Manaus, 07 de agosto de 1940. p.1.
} 
como, os pequenos serviços de reparos e mobiliário no prédio, sempre sob orientação dos professores de acordo com as oficinas ${ }^{12}$.

A admissão na Escola se fazia por meio de matrículas solicitadas pelos pais ou responsáveis pelas menores, sendo também admitidas as encaminhadas pelo Juízo de Menores. O Regulamento estabelecia que somente poderiam ser aceitas aquelas na faixa etária entre oito a dezoito anos. $\mathrm{O}$ asseio pessoal recebido pela menor ao ingressar no estabelecimento marcava a sua condição interna ${ }^{13}$.

$\mathrm{O}$ ato de submeter o interno ao banho, ao corte de cabelo, dentre outros, não deve ser percebido como simples ações higiênicas, pois como sustenta Erving Goffman em sua análise sobre instituições totais, ao adentrar um estabelecimento disciplinar, o interno é levado a se desfazer de tudo aquilo que possa trazer do mundo do qual está sendo apartado. Caso tenha objetos eles são confiscados e deixados sob os cuidados da direção 14. Para Goffman, o banho seria uma forma de desinfecção, muitas vezes acompanhados do corte de cabelo. A adoção de uniforme fazia parte do complemento de uma assepsia que tinha como finalidade eliminar qualquer vestígio do mundo anterior do interno. A proibição de saída do estabelecimento e do recebimento de visitas, assinala "uma ruptura profunda com o papel social anterior". Assim, lentamente vai sendo instalada a deformação pessoal, a perda de identidade, a perda do eu. Para Goffman, "as instituições totais são as estufas de nossa sociedade para mudar pessoas"15.

A vigilância e disciplina dentro da Escola Premunitória era permanente. Sob observação todas as horas do dia, as alunas deveriam atentar para as medidas de higiene se apresentando sempre asseadas. O silêncio e a ordem eram exigidos nas aulas, nas salas de estudo e no refeitório. A preocupação com a disciplinarização e o respeito à hierarquia se evidenciava no regulamento ao estabelecer que as alunas ao se dirigirem a professora em sala de aula, "levantarão o braço direito com a mão aberta, aguardando que sejam atendidas, e, quando chamadas a ler ou responder, fá-la-ão de pé”. Para saírem da sala deveriam aguardar o sinal da professora, sendo "o primeiro para guardar livros ou utensílios, o segundo para se levantarem, e o terceiro, para seguirem, saindo,

\footnotetext{
${ }^{12}$ Diário Oficial, $\mathrm{n}^{\circ}$ 13.505. Manaus, 07 de agosto de 1940. p.2.

${ }^{13}$ Diário Oficial, $n^{\circ} 13.505$. Manaus, 07 de agosto de 1940. p. 1 a 3.

${ }^{14}$ GOFFMAN, Erving. Manicômios, Prisões e Conventos. São Paulo: Perspectiva. 2003.7 ${ }^{\mathrm{a}}$ ed. Goffman considera instituição total como "um local de residência e trabalho onde um grande número de indivíduos com situação semelhante, separados da sociedade mais ampla por considerável período de tempo, levam uma vida fechada e formalmente administrada". p.11.

${ }^{15}$ GOFFMAN, Erving. Manicômios, Prisões e Conventos. São Paulo: Perspectiva. 2003.7ª ed. p.11
} 
primeiramente, a fila da frente, depois a imediata, a um de fundo"16. Para Erving Goffman, esses métodos utilizados em estabelecimentos disciplinares, eram formas de retirar a autonomia de ação dos sujeitos internos. Isso se fazia diariamente, regulamentando o tempo a ser dispendido nas atividades mais corriqueiras sob pena de sanções em caso de não cumprimento ${ }^{17}$.

Seguindo essa perspectiva de análise, acreditamos que a Escola Premunitória do Bom Pastor tenha sido espaço de permanente tensão entre alunas e funcionárias, e entre as próprias alunas, visto algumas delas exercerem cargos de vigilância. Este seria o caso das alunas guardas e das alunas porteiras. Caberia as primeiras, dentre outras funções, garantir que as alunas seguissem as medidas de higiene recomendadas, se comportassem de forma adequada nas aulas, no refeitório e dormitório, podendo admoestá-las quando necessário. Deveria fazer um registro por escrito de todas as faltas cometidas pelas alunas e apresentar para a administradora da Escola. Às alunas porteiras caberia, dentre outras atribuições, a vigilância do portão de acesso da instituição, não permitindo a saída ou entrada sem autorização, bem como garantir que toda correspondência recebida e enviada primeiramente passasse pela direção ${ }^{18}$. Entendemos que se por um lado as alunas responsáveis pela vigilância e controle da entrada e saída da Escola poderiam permitir ou ignorar a burla das normas da instituição praticadas por outras alunas, por outro lado elas atuavam como agentes repressoras/opressoras a serviço da própria instituição. Para além disso, um cargo de vigilância ocupado por uma aluna poderia significar uma tática para se abster da realização de serviços mais pesados, ainda que por conta desses pequenos privilégios devesse mostrar rigor no exercício de suas funções ante as demais internas, sob pena de punição caso não cumprisse as exigências do cargo. Nesse sentido, o cotidiano dentro da Escola seria um espaço de tensão permanente no qual alunas e direção criavam e recriavam formas de sobrevivência que lhes garantisse melhores condições de vida dentro do estabelecimento disciplinar.

\footnotetext{
${ }^{16}$ Diário Oficial, $\mathrm{n}^{\circ}$ 13.505. Manaus, 07 de agosto de 1940. p.3.

${ }^{17}$ Goffman cita como exemplo uma cadeia para jovens delinquentes nos Estados Unidos, na qual, logo após o raiar do dia, em pé, ao lado da cama, cada interno teria que realizar tarefas em curto espaço de tempo previamente estabelecido, sob o sinal de um guarda. Quando ele gritava " “UM”, nós tirávamos o pijama; "DOIS", dobrávamos o pijama; "TRÊS", arrumávamos a cama. [...]". "Também nos vestíamos com números: camisa com "UM!", calças com "DOIS!”, meias com “TRÊS!”, sapatos com” QUATRO!”. Qualquer ruído, como por exemplo, derrubar um sapato ou até esfrega-lo no chão seria o suficiente para repreensão". GOFFMAN,. Manicômios, Prisões e Conventos...op.cit. p.42.

${ }^{18}$ Diário Oficial, $\mathrm{n}^{\circ}$ 13.505. Manaus, 07 de agosto de 1940. p.1
} 
Algumas reações parecem ter sido comuns em espaços de reclusão nos moldes da Escola Premunitória, o que justificaria constar no regulamento como expressamente proibidas. São elas:

\begin{abstract}
"proferir impropérios, clamar, brigar, fomentar rixa, perturbar as colegas em serviços ou brinquedo, provoca-las na classe ou em forma, sair sem permissão, sujar de qualquer maneira o chão, paredes, móveis, falar alto, palestrar em hora de trabalho, assobiar em horas impróprias, afastar-se do estabelecimento, discutir ordens ou desacatar a autoridade das mestras, professores e superiores hierárquicos, apropriar-se ou lançar mão de objeto alheio, tentar ou praticar contra a moral e o pudor ou a integridade física de outrem, dar denúncia ou testemunho falso, deixar seus objetos escolares, indumentárias, ferramentas, etc., em abandono ou fora de lugares que lhe são próprios e em desalinho, o leito e demais pertences de quarto, urinar fora das respectivas privadas ou vaso, cuspir ou salivar nas dependências do pavilhão, sujar ou rasgar a roupa fora do serviço ou por descuido, descuidar dos objetos de seu uso no refeitório, sujar propositalmente as toalhas de mesa e de quarto; expedir cartas sem o necessário visto da administradora, passar dolosamente seu serviço a outra, ; são atos passiveis das penas que trata esse regulamento" 19 .
\end{abstract}

Entendemos que a preocupação em detalhar no regulamente as ações consideradas como infrações, advém de experiências anteriores em outras instituições. Ou seja, que tais reações fossem esperadas da parte dos reclusos, no caso, as educandas da Escola Premunitória. Isso se mostra muito significativo pois possibilita perceber as pessoas envolvidas em estabelecimentos de reclusão disciplinar, como agentes que agiam, reagiam e manifestavam suas insatisfações dentro de suas possibilidades de ação. Pequenas ações de recusas diárias, que, caso não coibidas, poderiam inviabilizar a ação disciplinar dentro do estabelecimento. Pequenas ações que precisavam ser combatidas de forma a servir de exemplo e de inibir novas atitudes que demonstrassem insubmissão. Nesse sentido, as educandas que infringissem as normas da Escola estariam sujeitas as seguintes penas:

\footnotetext{
"advertência; punição em particular; punição condicional para ser aplicada em caso de reincidência; admoestação em público; privação de recreio, privação de recreio com trabalho, até três dias, separação temporária do grupo de alunas, isolamento com trabalhos escritos adequados ao ensinamento moral; isolamento "sine-die"; suspensão ou privação de cargos administrativos ou substituição de postos; privação de recreio com trabalho; mais de três dias; multa" 20 .
}

Como recompensa estava estabelecido o louvor perante a classe; nome no quadro de honra; postos, terreno para cultura, nomeação para contramestra de oficina ou de cultura e nomeação para os cargos vagos ${ }^{21}$. Das recompensas oferecidas chamava atenção

\footnotetext{
${ }^{19}$ Diário Oficial, $\mathrm{n}^{\mathrm{o}}$ 13.505. Manaus, 07 de agosto de 1940. p.3

${ }^{20}$ Diário Oficial, $\mathrm{n}^{\mathrm{o}} 13.505$. Manaus, 07 de agosto de 1940. p. 3.

${ }^{21}$ Diário Oficial, ${ }^{\circ}$ 13.505. Manaus, 07 de agosto de 1940. p.3,4.
} 
o recebimento de área para o cultivo de hortas que, por meio da venda dos produtos seria revertido integralmente para aluna. Dessa forma se pretendia estimular o interesse pelo ganho, o interesse pelo trabalho que poderia ser convertido em valor econômico.

A Escola oferecia outras formas de envolver as alunas no interesse pelo trabalho, com possibilidade de ganho real. Enquanto outras instituições disciplinadoras deixavam explicito que a finalidade seria a disciplinarização da criança por meio da reclusão, no sentido de reeducá-la, possibilitando o seu retorno ao convívio social enquanto ser produtivo, como veremos mais adiante, o regulamento da Escola Premunitória, estabelecia que o trabalho seria o elo que ligaria as educandas, ainda enquanto internadas, com a vida real em sociedade ${ }^{22}$. Seria por meio do trabalho que ocorreria a reabilitação, despertando nas pequenas o interesse em se tornarem e manterem-se laboriosas. Nesse sentido, para que as alunas reconhecessem a importância do trabalho, de todo o material produzido por elas $50 \%$ deveria ficar com elas como forma de estímulo, no sentido de despertar o desejo para adquirir cada vez mais. Como prêmio àquelas que demonstrassem reeducadas poderiam sair da instituição uma vez por mês para fazer compras, porém nunca desacompanhada ${ }^{23}$. Entendemos que permitir a saída das educandas para compras pessoais, poderia ser uma forma de despertar nessas meninas o prazer pelo consumo, demonstrando como algumas necessidades poderiam ser supridas pelo resultado do trabalho.

Com um pouco mais de um mês de funcionamento da Escola Premunitória, no Jornal do Comércio o Juízo de Menores informava que "25 mocinhas haviam sido encaminhadas para a instituição"24. Para além de propagar a atuação do Juízo e a utilidade da Escola, tal anúncio seria uma forma de advertência àquelas que insistissem em comportamentos indesejáveis. Poucos meses depois, seriam mais de cinquentas meninas internadas na instituição ${ }^{25}$. O número crescente de meninas encaminhadas pode sugerir não apenas a determinação do Juízo de Menores na sua tentativa de projeto civilizador, quanto a recusa dessas pequenas ao enquadramento social exigido.

Embora sem os recursos desejados alguns trabalhos foram desenvolvidos na Escola, habilitando as menores nos serviços de costura, bordado e cozinha. O aniversário de um ano de funcionamento da escola foi festejado com uma exposição dos trabalhos

\footnotetext{
22 Diário Oficial, $\mathrm{n}^{\circ}$ 13.505. Manaus, 07 de agosto de 1940. p.1

${ }^{23}$ Diário Oficial, $\mathrm{n}^{\circ}$ 13.505. Manaus,07 de agosto de 1940. p.1.

${ }^{24}$ Jornal do Comércio, $n^{\circ}$ 12134. Manaus, 23 de junho de 1940. p.1.

${ }^{25}$ Jornal do comércio, ${ }^{\circ} 12134$. Manaus, 29 de novembro de 1940. p.1.
} 
manuais confeccionados pelas educandas ${ }^{26}$. Tais trabalhos seriam expostos para vendas e encomendas. Os serviços de costura realizados por encomendas para outros órgãos públicos, contribuíam financeiramente, ainda que de forma precária, para funcionamento da Escola. Por todo o período pesquisado, o lamento pela falta de recursos adequados esteve sempre presente nas falas do Juiz de Menores e na imprensa que não deixava de tecer elogios a obra de correção de meninas consideradas desajustadas socialmente ou em perigo de vir a ser.

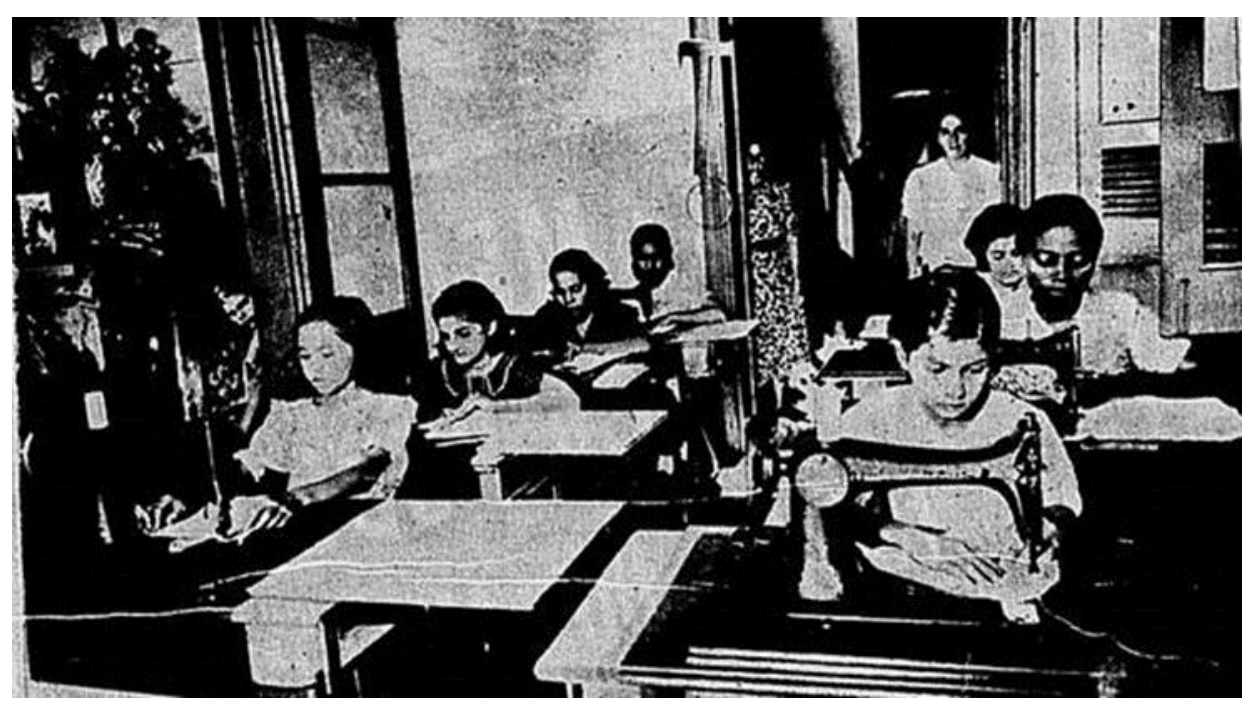

Imagem 1: Secção de costura da Escola Premunitória do Bom Pastor. Fonte: A Noite. 1.12.1942. Acervo: Hemeroteca Digital da Biblioteca Nacional

A Escola Premunitória, ao nosso ver, possuía como finalidade última o preparo de meninas para o tipo de trabalho considerado afeito as mulheres das famílias empobrecidas: o trabalho doméstico. Por meio da reclusão se pretendia incutir o amor ao trabalho, a submissão e aprendizagem de um ofício. Reforça nossa reflexão o artigo do regulamento que estabelece que, quando as educandas demonstrassem completamente reeducadas, poderiam ser encaminhadas às casas de famílias que, em troca de seus serviços, pagariam uma mensalidade integral à educanda. Esse compromisso deveria ser assinado formalmente por aquele que viesse a se responsabilizar por elas. "Caso os modos da educanda não o agradassem ele poderia devolvê-la à Escola Premunitória e trocar por outra, desde que não lhe tenha feito mal"27. Cremos não ser reducionismo afirmar, que a Escola Premunitória funcionou como agenciadora de mão de obra feminina infantojuvenil. No período de quatro anos após sua fundação, a Escola Premunitória contava

\footnotetext{
${ }^{26}$ Conselho de assistência e proteção aos Menores, $n^{\circ}$ 106. Manaus, 12.05.1941.

${ }^{27}$ Diário Oficial, ${ }^{\circ}$ 13.505. Manaus, 07 de agosto de 1940.p.1
} 
com oitenta alunas internadas, sendo que pelas dependências da instituição já haviam passado 250 meninas $^{28}$.

No ano de 1944, o então Juiz de Menores, Arnoldo Carpinteiro Peres, considerou a Escola Premunitória como o único instituto subordinado à Justiça de Menores satisfatoriamente organizado. Sob a direção de uma congregação religiosa, o ensino ministrado nesse estabelecimento era o das primeiras letras, a educação moral e cívica, sendo o "instituto nada mais que uma espécie de escola doméstica embrionária"29. O número de mátriculas se mantinha insuficiente para atender a procura por vagas na Escola, sendo necessário reduzir o número de internas devido à ausência de recursos financeiros para os gastos com alimentação e vestuário.

Os sujeitos submetidos a processos de disciplinarização não são inertes e passivos diante dos tentáculos das instituições que tentam lhe moldar corpos e mentes ${ }^{30}$. Entendemos que eles agem e reagem dentro das suas condições concretas e que, no seu dia-a-dia, eles criam e recriam práticas, dando outras funções aquilo que o Estado lhes impõe. Foi nesse sentido que muitas famílias pobres viram na Escola Premunitória a possibilidade de garantir alimento, abrigo e aprendizagem para suas filhas. Nessa perspectiva, muitas famílias procuraram interná-las como forma de tentar oferecer melhores condições de vida, ainda que a vida na instituição fosse sinônimo de vigilância e trabalho. Essa análise pode ser ilustrada no anúncio de um jornal de 1948, no qual a direção da Escola Premunitória do Bom Pastor solicitava encarecidamente que as famílias não procurassem vagas para suas filhas na Escola pois as 65 vagas estavam preenchidas, havendo uma pequena lista de aspirantes aguardando por matrícula ${ }^{31}$.

Diante disso, acreditamos que ao analisarmos processos de disciplinarização, não devemos percebê-los apenas a partir das medidas impositivas e repressivas para aqueles que se pretende disciplinar. Àqueles a quem tais medidas são direcionadas, agem, reagem, resistem, reelaboram e não raras vezes tiram proveito próprio quando assim se

\footnotetext{
${ }^{28}$ Interventoria Federal no Estado do Amazonas. Exposição apresentada a Getúlio Vargas por Álvaro Maia (Maio de 1943 a julho de 1944). Manaus: D.E.I.P. 1944, p.102.

${ }^{29}$ Justiça de Menores de Manaus. Relatório apresentado ao Interventor Federal no Amazonas, pelo Juiz Tutelar de Menores e Diretor Técnico do Serviço de Assistência Social (Período:19/fevereiro/1944 a 31/março/1945). Manaus: Tip. Da Liv. Normalista, p.8. IGHA.

${ }^{30}$ Para Michel Foucault, "o poder funciona e se exerce em rede. Nas suas malhas os indivíduos não só circulam, mas estão sempre em posição de exercer este poder e de sofrer sua ação; nunca são o alvo inerte ou consentido do poder, são sempre centros de transmissão”. FOUCAULT, Michel. Microfísica do Poder. Rio de Janeiro: Edições graal, 1979.p. 183.

${ }^{31}$ Jornal do Comércio, n $^{\circ} 14789$. Manaus, 01 de julho de 1948. p.3.
} 
mostra possível e desejável ${ }^{32}$. É “via" de mão dupla, onde os sujeitos sociais afetados as recebem de modo satisfatório quando é de seus interesses, rejeitando quando não lhes convém. Ilustra nossa reflexão o elevado número de pais que recorriam ao Juízo de Menores em busca de auxílio. Assim, diariamente passavam pelas dependências do Juízo não apenas "mulheres que solicitam internamento de menores em colégio", como também era elevado o número de "pobres que imploram esmolas, livros de estudos para seus filhos, roupas para as crianças, leite, remédio, etc" ${ }^{33}$. Nesse sentido, os processos de disciplinarização apresentam distintos matizes cabendo ao historiador perceber as diferentes nuanças, como e porque se manifestam.

No ano de 1948, o Governo do Estado entregou oficialmente, sob contrato, a administração da Escola Premunitória a Diocese de Manaus. Dentre as cláusulas contratuais a obrigação do governo do estado repassar subsídios para a Arquidiocese que, em contrapartida, se comprometia a reservar 65 vagas para meninas entre 12 e 18 anos, encaminhadas pelo Juízo de Menores ${ }^{34}$.

\section{Secção de Menores Melo Matos}

No mês de maio de 1939, o Interventor Federal do Estado do Amazonas, Álvaro Maia, criou a Secção de Menores Melo Matos, destinada a menores delinquentes. Instalada nas dependências da Cadeia Pública da cidade de Manaus, a Secção de Menores teria entrada exclusiva pela parte lateral no sentido de tentar manter essa Secção completamente separada da ala dos criminosos comuns ${ }^{35}$. Ao Juiz de Menores caberia a administração, bem como, a elaboração do regulamento do referido estabelecimento. $\mathrm{O}$ Interventor reconhecia que as instalações não seriam adequadas para o fim a que se destinavam, no entanto, "a situação do Estado presentemente, não permite, a criação de um reformatório para a readaptação social dos menores delinquentes" ${ }^{\text {36 }}$. O jornal A Tarde recebeu com júbilo o decreto interventorial. Enaltecendo a criação da Secção de Menores, louvava o fato de vir a "preencher uma indiscutível lacuna em nossa organização

\footnotetext{
32 CERTEAU, Michel de. A invenção do cotidiano: artes de fazer. Trad. de Ephraim Ferreira Alves. Petrópolis, RJ: Vozes, 1994.

${ }^{33}$ ARAÚJO,. Proteção à infância e a juventude no Amazonas de hoje...op.cit. p.10.

${ }^{34}$ Mensagem do Governador Leopoldo Neves apresentado a Assembleia - 1948. Manaus: Imprensa Oficial, 1948. p.102.

${ }^{35}$ Diário Oficial. Manaus, 16 de maio de 1939. p.23. A criação de uma secção de menores estava prevista no Decreto-Lei de criação do Juízo de Menores, que seguindo as determinações do Código de 1927, estabelecia que os menores abandonados e delinquentes poderiam ser recolhidos ao Patronato Agrícola do Estado (Paredão) ou a uma secção de menores a ser criado pelo Governo do Estado, ficando os menores sob a responsabilidade do Juiz ${ }^{35}$.

${ }^{36}$ Diário Oficial do Amazonas. Manaus, 16 de maio de 1939. p.23.
} 
judiciária e penal, evitando os embaraços decorrentes para a justiça de menores da promiscuidade dos delinquentes infantis com os criminosos adultos, num regime penitenciário comum"37.

A documentação citada levanta algumas questões apontadas em pesquisas anteriores, indicando a permanência, ainda na década de 1930, da inexistência de espaços distintos para aqueles reclusos por lei. Na maioria das vezes, adultos e crianças recolhidos por pequenas infrações como mendicância, vadiagem, etc, provavelmente eram recolhidos a Cadeia Pública sem que houvesse preocupação em separá-los por gravidade do delito cometido, por idade ou por sexo.

O corpo administrativo da Secção estava composto pelos funcionários da Casa de Detenção, com exceção do inspetor vigilante, do médico, do professor e do dentista, indicados pelo Juiz. Diariamente sob rigorosa vigilância, os menores seriam observados, examinados, analisados, sendo transcrito em livros de registro seu perfil psicológico "contendo seus vícios, suas virtudes, afeições, tendências, os efeitos do regime educativo disciplinar", etc, ${ }^{38}$.

Ao analisarmos o Regulamento da Secção Melo Matos, nos deparamos com itens estabelecendo que aos menores que passavam por suas dependências deveria ser oferecida uma vida relativamente saudável, um ambiente limpo e sadio, tanto no que se refere a estrutura física quanto ao que se refere a alimentação. De forma semelhante deveria ser o relacionamento entre funcionários e menores apreendidos. A estes, ainda segundo o regulamento, seria dispensado tratamento respeitoso e afável, considerando a personalidade de cada criança e jovem recolhido. Sendo a instituição um espaço de reforma, de regeneração, as boas maneiras e os bons valores deveriam fazer parte do aprendizado. Se eles haviam sido recolhidos pela recusa ao enquadramento social que exigia o respeito a hierarquia, o amor ao trabalho e a pátria, deveria ser ensinado "a respeitar e honrar as tradições, amar o trabalho e a proceder de modo que mereçam a estima e afeição dos seus companheiros e superiores" 39 .

A Secção, provisoriamente, receberia apenas crianças e jovens do sexo masculino, o que demonstrava a intenção de futuramente criar um lugar específico para mulheres ${ }^{40}$. Quanto ao regime disciplinar da Secção, estavam terminantemente proibidos os castigos

\footnotetext{
${ }^{37}$ A Tarde, $n^{\circ}$ 685. Manaus, 17 de maio de 1939, p.1.

${ }^{38}$ Diário Oficial, $\mathrm{n}^{\circ}$ 13.215. Manaus, 10 de agosto de 1939. p. 3.

${ }^{39}$ Diário Oficial, $\mathrm{n}^{\circ}$ 13.215. Manaus, 10 de agosto de 1939. p. 3.

${ }^{40}$ Diário Oficial, $\mathrm{n}^{\circ}$ 13.215. Manaus, 10 de agosto de 1939. p. 3. A criação de um estabelecimento correcional específico para menores do sexo feminino estava prevista no Código de menores de 1927.
} 
corporais ou qualquer manifestação de humilhação ao recluso. As posturas consideradas inadequadas, a burla das normas deveria ser reprimida por meio de admoestação branda. A recusa frequente ao não cumprimento das regras estabelecidas resultaria em sanções tais como a privação do recreio, de receber visitas ou correspondência, detenção em sala própria para esse fim e "recolhimento até quinze dias, no máximo, a um compartimento de isolamento, ao qual sairá somente para as aulas e alguns trabalhos". As recompensas se traduziriam em boas notas, elogios, prêmios em forma de livros ou brinquedos ${ }^{41}$.

As sanções e prêmios impostos como dispositivo disciplinar àqueles que não seguissem as normas do estabelecimento para além de indicar a não aceitação da reclusão por parte dos internados, indicava a exclusão dentro do próprio espaço de reclusão. Crianças e jovens eram retirados do convívio em sociedade e recolhidos à reclusão disciplinar com a finalidade de incutir normas sociais considerados fundamentais: amor ao trabalho, respeito pela hierarquia, sentido de disciplina, etc. No entanto, dentro do próprio estabelecimento disciplinar, espaço de reclusão, o internado que se recusasse a seguir as normas do estabelecimento ficaria encarcerado em um compartimento isolado dos demais ${ }^{42}$.

A documentação não permite precisar o perfil das crianças recolhidas à Secção Melo Matos, no entanto, considerando que elas eram encaminhadas pelo Juízo de Menores, sugerimos que a maior taxa de internados seria de amazonenses e descendentes de indígenas. Quanto à idade desses pequenos, embora o Regulamento não estabeleça idade mínima para ser internado na instituição, as fotos de meninos internos revelam crianças que aparentavam pouca idade, como podemos observar na fotografia publicada em 1942, no Rio de Janeiro, no jornal A Noite, ao propagandear os feitos do interventor Álvaro Maia. Na imagem, os internos se encontram perfilados a frente da Cadeia Pública de Manaus, local onde funcionava o estabelecimento.

\footnotetext{
${ }^{41}$ Diário Oficial, $\mathrm{n}^{\circ}$ 13.215. Manaus, 10 de agosto de 1939. p. 3

${ }^{42}$ Em literatura sobre o período, Jorge Amado ao se referir ao compartimento de isolamento de um reformatório na Bahia, o descreve como um quarto de dimensões muito reduzidas, não possibilitando que o enclausurado permanecesse em pé ou deitado. Totalmente cerrado, a escuridão era a única companhia não permitindo identificar quando era noite ou dia. AMADO, Jorge. Capitães da Areia. São Paulo: Companhia das Letras, 2008. P. 203.
} 


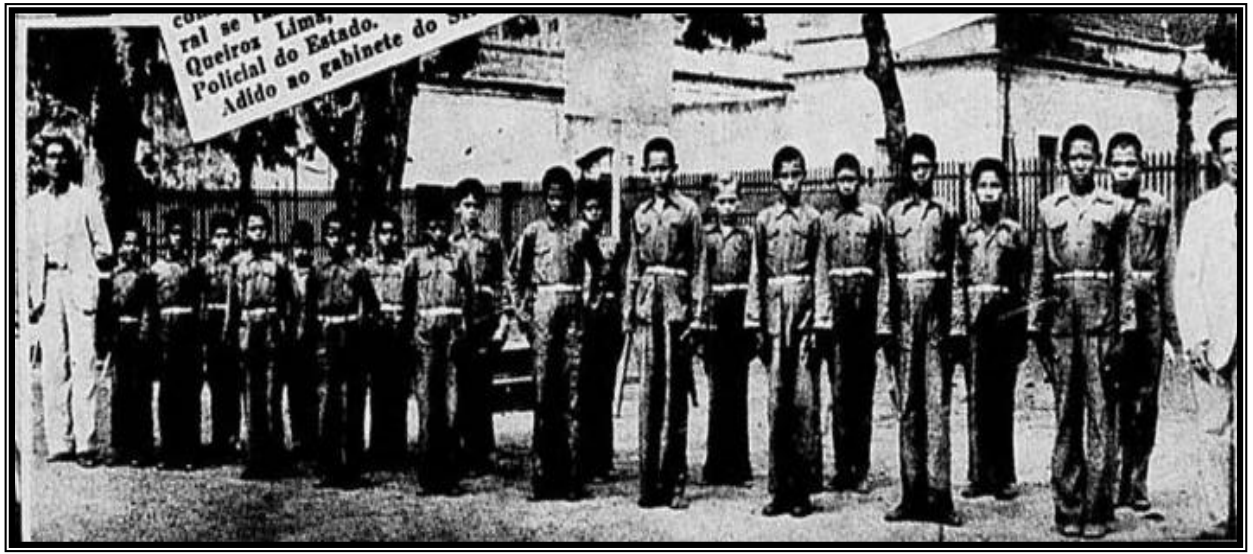

Imagem 2: Menores internos da Secção Melo Matos em traje de desfile cívico. Fonte: A Noite. 1.12.1942. Acervo: Hemeroteca Digital da Biblioteca Nacional

Com cerca de um ano de criação, embora funcionando em condições precárias, a Secção Melo Matos havia recebido 43 menores $^{43}$. Tudo indica que a preocupação inicial seria retirar crianças e jovens considerados delinquentes das ruas da cidade submetendoos a um severo regime de reclusão e vigilância, ainda que a instituição criada para esse fim não estivesse adequada para recebê-los nem houvesse recursos para oferecer-lhes educação e o ensino de um ofício. Nesse sentido, a propalada ideia de reeducação não funcionava na prática. Acreditamos que a finalidade primeira seria a segregação desses menores e não a reeducação.

Em 1940, durante a visita de Getúlio Vargas à Manaus, André Vidal de Araújo, Juiz de Menores, entregou ao presidente um memorial no qual discorria sobre as ações do Juizado de Menores na capital amazonense e solicitava recursos para caminhar com os projetos iniciados. Sobre a Secção se referia como:

\footnotetext{
“modesta, pobremente aparelhada, mesmo assim vai servindo, e belamente, às suas finalidades educacionais [...] os menores, ali recebem uma instrução primária de urgência, bem assim leves conhecimentos de marcenaria, e que se constituem desse jeito, valores reais dentro da realidade brasileira" ${ }^{44}$.
}

A fala do Juiz nos leva a refletir sobre o que seriam os valores reais dentro da realidade brasileira. A educação para os filhos das famílias pobres apenas o suficiente para aprendizagem de um ofício, ainda que de forma rudimentar. Pode indicar, também, que essas crianças passavam boa parte do dia na ociosidade dentro da Secção ou realizando serviços fora da instituição. Em 1942 a instituição inaugurou as oficinas de encadernação, marcenaria e sapataria, passando a receber encomendas externas. Além da

\footnotetext{
${ }^{43}$ Jornal do Comércio, no 12134. Manaus, 23 de junho de 1940, p.1.

${ }^{44}$ ARAÚJO, André Vidal. A Prol da Infância: apelo do Juiz de Menores de Manaus, Dr. André Vidal de Araújo ao Presidente Getúlio Vargas. Manaus: 1940. p.8
} 
aprendizagem de um ofício, passou a garantir, por meio dos trabalhos dos internados "os lucros revestidos em benefício daquela casa, tais as encomendas constantes que está recebendo de fora" ${ }^{45}$. Dessa forma se fazia uso da força de trabalho das crianças dentro das instituições de modo a compensar os gastos com a sua permanência dentro do estabelecimento. Cremos que a isso podemos denominar de reembolso compulsório.

Não raramente, o trabalho desses pequenos poderia ser utilizado fora dos muros de reclusão. Assim ocorreu durantes os serviços de construção de um parque infantil para as crianças pobres, promovido pelo Juízo de Menores. Desse modo, o Jornal do Comércio informava que após conseguir a doação de um terreno apropriado para as instalações, "os primeiros trabalhos nesse sentido, já estão sendo feitos pelos próprios correcionais da Escola Melo Matos” juntamente com uns meninos do Bairro da Cachoeirinha ${ }^{46}$. Isso indica a permanência de crianças exercendo atividades em obras públicas mesmo que tal atividade fosse proibida pelo Código de Menores. A presença de crianças nas construções públicas da cidade, parecia não chocar a população, sendo por nós encontrada vestígios desde o século XIX. Para o Período Provincial, a tabela para pagamento dos operários da Obras Públicas incluía o preço a ser pagos a meninos com até doze anos de idade que exerciam a função de serventes ${ }^{47}$. Isso evidencia que poderia não haver uma idade mínima para eles adentrarem nesse tipo de trabalho. No período republicano encontramos meninos exercendo função de auxiliar de carpintaria e meninas como servente nas obras públicas $^{48}$. O fato das crianças internadas na Secção Melo Matos participarem da construção de um parque infantil juntamente com outras crianças, para além de indicar o uso dessa força de trabalho pelo próprio Juizado de Menores, pode sugerir que o uso dessa mão-de-obra em serviços externos não fosse incomum.

Não obstante as punições previstas, o cotidiano dentro desses estabelecimentos disciplinares não raras vezes poderia se tornar palco de enfrentamento entre os internos e superiores, onde aqueles demonstravam de diferentes formas a recusa ao enquadramento imposto pela instituição. Assim fica evidenciado pela Portaria $\mathrm{n}^{\circ} 403$, publicada pelo Juízo de Menores em 1942, estabelecendo penalidades para aqueles que fizessem uso de

\footnotetext{
${ }^{45}$ Conselho de Assistência e Proteção aos Menores, $n^{\circ}$ 136. Manaus, 17 de março de 1942.

46 Jornal do Comércio, no 12212 . Manaus, 22 de setembro de 1940. p.1.

${ }^{47}$ Livro da Repartição de Obras Públicas da Província do Amazonas - 1864 (Manuscritos). Arquivo Público do Estado do Amazonas.

48 PESSOA, Alba Barbosa. Meninas nos Mundos do Trabalho: um olhar através da imprensa manauara (1890-1920). In: PINHEIRO, Maria Luiza Ugarte (org.). Gênero e Imprensa na História do Amazonas. Manaus: EDUA, 2014. p. 61-70.
} 
vocabulário considerado obsceno, pela não observância a hierarquia e para aqueles que deliberadamente danificavam os instrumentos das oficinas do estabelecimento ${ }^{49}$.

A ausência de atendimento adequado aos menores internos foi permanente em todo o período por nós pesquisado sendo de conhecimento público a precariedade das instalações do estabelecimento correcional, bem como, da alimentação insuficiente e inadequada oferecida aos internados. Como reconhecia o Procurador Geral do Estado do Amazonas em 1943, “a alimentação fornecida pela penitenciária, não pode, naturalmente, corresponder ao regime dietético, adequado a criança"50. Talvez as notícias sobre as condições as quais se encontravam submetidos os recolhidos ao Instituto Melo Matos, despertasse verdadeiro pavor ante a chegada dos Vigilantes de Menores nas ruas da cidade. Crianças e suas famílias viviam em permanente estado de apreensão, conforme revela Hilton de Oliveira Rego, ao lembrar de sua infância vivenciada em Manaus na década de 40:

\begin{abstract}
Naquela época em Manaus existia uma repressão enorme e constante por parte das autoridades que controlavam a infância e a juventude através da instituição chamada Instituto Melo Matos, cujos guardas saiam as ruas diariamente pela cidade toda à procura de meninos ou meninas que estivessem brincando na rua. Se os pegassem em flagrante eram levados presos para Casa de Detenção [...]. Em seguida convocavam os pais dos menores para pagar multa, sem a qual, o filho ou filha não era liberado, sem antes passar uma descompostura nos responsáveis e fichar o detento ${ }^{51}$.
\end{abstract}

De acordo com o memorialista, na terceira reincidência eram encaminhados ao Instituto. Tais ações eram acompanhadas da violência física pois "eles vinham em silêncio sempre em grupo, em uma caminhonete grande preta, saltando rápido e empunhando cassetetes de borracha para bater em quem resistisse à prisão"52. A fala do autor demonstra o quão as crianças e jovens resistiram às normas disciplinares, pois ainda que houvesse o temor de ser recolhido ao Instituto, grande parcela se arriscava em permanecer nas ruas exercendo suas formas de sociabilidade.

No ano de 1944, haviam passado pelo Instituto Melo Matos cerca de 524 menores considerados delinquentes e abandonados. Destes, o maior número era de abandonados sendo a maior parcela recolhida por vadiagem e pequenos furtos, enquanto um índice muito reduzido foi motivado por homicídio ou atentado a vida. De acordo com os dados da Exposição apresentada por Álvaro Maia ao presidente Getúlio Vargas, o Instituto Melo

\footnotetext{
${ }^{49}$ Conselho de Assistência e Proteção aos Menores, $n^{\circ}$ 135. Manaus, 9 de março de 1942

${ }^{50}$ Conselho de Assistência e Proteção aos Menores, ${ }^{\circ}$ 169. Manaus, 15 de maio de 1943.

${ }^{51}$ REGO, Hilton de Oliveira. Com a Cara e a Coragem: uma aventura através da História. Rio de Janeiro: HEDRAIOS, 2010. p.27.

${ }^{52}$ REGO,. Com a Cara e a Coragem...op.cit. p.27.
} 
Matos contava com oficinas de sapateiro, marceneiro, tipógrafo, encadernação e ferreiro, tendo "entregue à sociedade amazonense muitos meninos reeducados, todos operários amparados em oficinas pelo próprio Juiz, que dispõe de uma Agência de colocação de menores" ${ }^{53}$. Nesse sentido, estaria o Amazonas contribuindo para a disciplinarização da infância, retirando das ruas braços ociosos e, por meio da disciplina e do trabalho, transformando-os em força laboriosa. Sendo esse projeto disciplinar voltado para os filhos das famílias empobrecidas a instituição reteve entre seus muros as crianças e juventude empobrecida da cidade de Manaus. Segundo o Jornal do Comércio de 1945, o Instituto Melo Matos cumpria o papel para o qual fora criado pois, nele se encontravam os "garotos endiabrados da cidade, meninos levados da breca, acostumados a quebrar vidraças das casas de burgueses, e meter-se em sarilhos com os quais nada têm a ver, a fumar, e alguns até cumprindo pena por agressão armada" 54 .

No entanto, a mudança de direção do Juízo de Menores, ocorrida ainda em 1944, revelou outras cores a atuação do Instituto Melo Matos junto a decantada regeneração e reeducação de crianças chamadas de delinquentes. O Instituto, de acordo como o relatório apresentado pelo então juiz Arnoldo Carpinteiro Peres, em nada cumpria com as finalidades para o qual fora criado. Arnoldo Peres alegava que ali imperava a ociosidade, oficinas em desuso e falta de uma política pedagógica-repressiva eficaz, não merecendo ter passado à condição de instituto visto não ter recebido nenhuma melhoria nas dependências de onde funcionava, sendo necessário toda uma reestruturação física do estabelecimento, bem como de uma nova organização do seu quadro funcional e pratica pedagógica $^{55}$. De acordo com o Juiz:

\footnotetext{
"nessa dependência da cadeia Pública, não se encontram instalações apropriadas, mesmo precariamente[...] com efeito, ali quase tudo falta para se proporcionar à infância e à juventude sob a nossa tutela os meios de leva-las ao caminho da regeneração, pois inexistem oficinas, enfermarias, dormitórios higiênicos, secretaria, fichários, etc, etc...mero depósito de menores, os quais quase nada recebem para fins regenerativos, lá se encontram apenas para evitar fiquem em promiscuidade com os delinquentes adultos" 56 .
}

\footnotetext{
${ }^{53}$ Exposição apresentada por Álvaro Maia ao presidente Getúlio Vargas (1943-1944). Manaus: D.E.I.P., 1944. p.101.

${ }^{54}$ Jornal do Comércio, $\mathrm{n}^{\circ}$ 13724. Manaus, 2 de janeiro de 1945. p.21.

55 Justiça de Menores de Manaus. Relatório apresentado ao Interventor Federal no Amazonas, pelo Juiz Tutelar de Menores e Diretor Técnico do Serviço de Assistência Social (Período:19/fevereiro/1944 a 31/março/1945). Manaus: Tip. Da Liv. Normalista, p.10.

56 Justiça de Menores de Manaus. Relatório apresentado ao Interventor Federal no Amazonas, pelo Juiz Tutelar de Menores e Diretor Técnico do Serviço de Assistência Social (Período:19/fevereiro/1944 a 31/março/1945). Manaus: Tip. Da Liv. Normalista, p.11.
} 
Sugeria o Juiz, como solução, a criação de um patronato agrícola, onde crianças e jovens encontrassem na prática camponesa o caminho do amor ao trabalho e da regeneração. Para Peres, o contato com o campo possibilitaria um processo de readaptação ao meio social além de em muito contribuir para o desenvolvimento da agricultura. Este era um problema antigo, a falta de braços e interesse pela agricultura. Dessa forma se pensava em resolver a escassez de gêneros alimentícios que assolava a capital amazonense. Somente assim, afirmava o Juiz, "poderemos devolver a sociedade elementos úteis e operosos, capazes de colaborarem no bem comum ${ }^{57}$.

Somente no ano de 1948, o Instituto Melo Matos foi retirado das dependências da Penitenciária passando a funcionar em um bairro afastado da cidade, nas proximidades do hospício Eduardo Ribeiro. Para o Juiz de Menores, o Instituto Melo Matos, até então, havia funcionado como verdadeiro campo de concentração. Pensamento este partilhado por parte da imprensa local, para quem as instituições mantidas pelo governo eram sinônimo de "garotos esfarrapados, de olheiras profundas, tristes e mal alimentados" 58 .

Diante do exposto, sugerimos que ambas instituições, Escola Premunitória do Bom Pastor e Secção Mello Mattos, são partes de uma extensa cadeia de estabelecimentos criada no sentido de efetivar um projeto voltado para as famílias empobrecidas, que visava, antes de tudo, forjar novas formas de ser e fazer. E para além disso, que tais famílias não o receberam de forma passiva ou inerte.

\footnotetext{
57 Justiça de Menores de Manaus. Relatório apresentado ao Interventor Federal no Amazonas, pelo Juiz Tutelar de Menores e Diretor Técnico do Serviço de Assistência Social (Período:19/fevereiro/1944 a 31/março/1945). Manaus: Tip. Da Liv. Normalista, p.15.

${ }^{58}$ Respectivamente: Mensagem de Governo - 1948. Manaus: Imprensa Oficial. 1948, p.93; Jornal do Comércio, n 14419. Manaus, 20 de abril de 1947, p.10; jornal do Comércio, nº 14722. Manaus, 14 de abril de 1948 , p.4.
} 


\section{Referências Bibliográficas}

AMADO, Jorge. Capitães da Areia. São Paulo: Companhia das Letras, 2008.

ARAÚJO, André Vidal. Proteção à Infância e a Juventude no Amazonas de Hoje: cinco anos em prol da infância desvalida (1935-1940). Manaus: Imprensa Pública, 1940.

ARAÚJO, André Vidal. A Prol da Infância: apelo do Juiz de Menores de Manaus, Dr. André Vidal de Araújo ao Presidente Getúlio Vargas. Manaus: 1940.

CERTEAU, Michel de. A invenção do cotidiano: artes de fazer. Petrópolis, RJ: Vozes, 1994.

FERLA, Luis. Feios, sujos e malvados sob medida: a utopia médica do biodeterminismo, São Paulo (1920-1945). São Paulo: alameda, 2009.

FOUCAULT, Michel. Microfísica do Poder. Rio de Janeiro: Edições graal, 1979.

GOFFMAN, Erving. Manicômios, Prisões e Conventos. São Paulo: Perspectiva. 2003.

PESSOA, Alba Barbosa. Pequenos Construtores da Nação: disciplinarização da infância na cidade de Manaus (1930-1945). Tese de Doutorado em História. UFPA: 2018.

PESSOA, Alba Barbosa. Meninas nos Mundos do Trabalho: um olhar através da imprensa manauara (1890-1920). In: PINHEIRO, Maria Luiza Ugarte (org.) Gênero \& imprensa na História do Amazonas. Manaus: EDUA, 2014.

REGO, Hilton de Oliveira. Com a Cara e a Coragem: uma aventura através da História. Rio de Janeiro: HEDRAIOS, 2010.

VASCONCELOS, Kelly Rocha de Matos. Parques Infantis no Amazonas: 1940 a 1946.

Dissertação de Mestrado em Educação. UFAM: 2018. 